University for Business and Technology in Kosovo

UBT Knowledge Center

UBT International Conference

2017 UBT International Conference

Oct 28th, 2:00 PM - 3:30 PM

\title{
Optimal Design of Grillage Structures with Steel Crossed Beams using Genetic Algorithms
}

\author{
Ersilio Tushaj \\ Polytechnic University of Tirana, ersilio.tushaj@gmail.com \\ Niko Lako \\ Polytechnic University of Tirana, nlako@yahoo.com \\ Fatjon Saliu \\ Polytechnic University of Tirana, tonsaliu@yahoo.com
}

Follow this and additional works at: https://knowledgecenter.ubt-uni.net/conference

Part of the Civil Engineering Commons

\section{Recommended Citation}

Tushaj, Ersilio; Lako, Niko; and Saliu, Fatjon, "Optimal Design of Grillage Structures with Steel Crossed Beams using Genetic Algorithms" (2017). UBT International Conference. 41.

https://knowledgecenter.ubt-uni.net/conference/2017/all-events/41

This Event is brought to you for free and open access by the Publication and Journals at UBT Knowledge Center. It has been accepted for inclusion in UBT International Conference by an authorized administrator of UBT Knowledge Center. For more information, please contact knowledge.center@ubt-uni.net. 


\title{
Optimal Design of Grillage Structures with Steel Crossed Beams using Genetic Algorithms.
}

\author{
Ersilio Tushaj ${ }^{1}$, Niko Lako $^{2}$, Fatjon Saliu ${ }^{3}$ \\ ${ }^{1,3} \mathrm{PhD}$ Candidate, Faculty of Civil Engineering, Polytechnic University of Tirana, \\ Albania. email. ersilio.tushaj@gmail.com, tonsaliu@yahoo.com \\ ${ }^{2}$ Professor of Steel Structures, PhD Program, Polytechnic Universiy of Tirana, \\ Albania.
}

Email.nlako@yahoo.com

\begin{abstract}
The structural engineering design problem consist in an iterative process of design. Various authors have analyzed the optimization of steel structures using different algorithmic approaches. These techniques are generally grouped in deterministic or meta-heuristics. From the introduction of structural optimization in the 1960' up to now, various methods have been proposed. A GA genetic algorithm, is built and applied in this study using MatLab soft R2017a to crossed beams systems. The structural analysis is done applying the direct stiffness method with constraints verification based on EuroCode 3:2005 criteria. Results are reported in the study.
\end{abstract}

Keywords: steel structures optimization, genetic algorithm, crossed beams.

\section{Introduction}

Steel crossed beams or plane grillages (Fig. 7) are simple space structures with similar behavior to steel frames, but with differences in the way the loads are applied to the scheme, which are perpendicular to the plane of the structure.

The design problem of the grillage structures consist in finding the appropriate sections for the longitudinal and transversal beams. In this study the Ultimate Limit State and Service Limit State of EuroCode 3: 2005 constraints are applied.

The optimal design problem automates the process. It's not the designer, who decide which section profiles should be verified; but it's the algorithmic process, which input the profiles from a standard commercial list and verify them to satisfy the given constraints. These include stresses, displacements and geometrical limits, expressed in terms of internal forces verifications and ultimate displacements.

The algorithmic iteration in this study is done applying the genetic algorithms or the GAs, which are part of the meta-heuristic optimization methods and evolutionary algorithms. They use computational models of evolution and selection. These mechanism of Darwinian evolution and natural selection are encoded in the algorithm.

Typically, an optimal design problem consist in: (a) objective function, (b) design variables, and (c) constraints [1]. The design variables are those parameters to be determined in order to generate an optimal solution. The objective function in this study is the total weight of the structure.

The process of sizing can be continuous or discrete. In this study the structural members are adopted from a set of available sections, so the design problem is a discrete sizing optimization. 


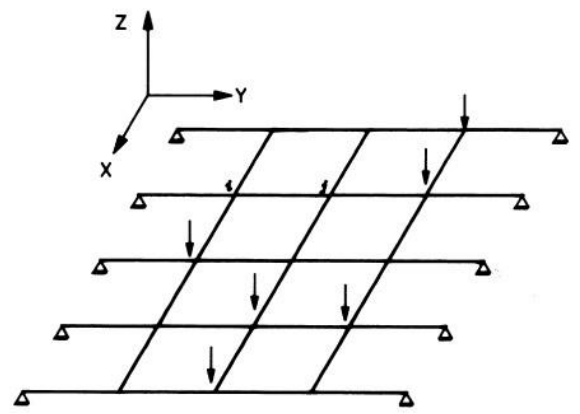

Fig. 7. General scheme of the grillage structure (crossed beams)

\section{Methodology}

The optimal design problem is built in MatLab soft R2017a, a numerical computing environment and a programming language, which allows matrix operations, plotting of functions and implementation of algorithms.

The "Global Optimization Toolbox" is installed in MatLab and the Genetic algorithm function @ ga is applied modifying some genetic parameters, such as: "PopulationSize", "MaxGenerations" and "EliteCount". The convergence criteria are imposed in terms of "FunctionTolerance", "MaxStallGenerations" or "MaxStallTime".

The structural analysis of the scheme is done applying the direct stiffness method The grillage structure is analyzed dividing the scheme in elements with three degrees of freedom for node: two rotations and one vertical displacements (Fig. 8).

For the GA design process is used a Portable Laptop i3 2.2 Ghz with 6 Gb Ram working on 40$60 \%$ of his potentiality.

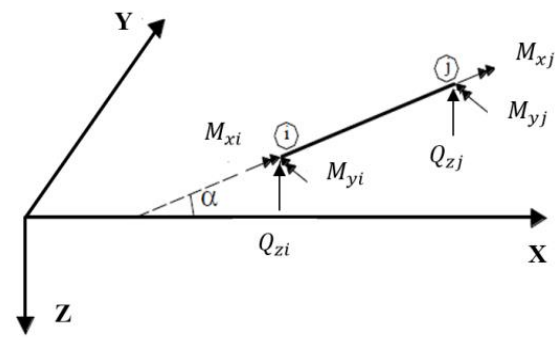

Fig. 8. Degrees of freedom of the (i-j)-th element

There are built three mayor Scripts: "Input data", "Crossed beams structural analysis" and "GA" and the following functions: "fitness functions", "internal forces", "stiffness matrix", "transformation matrix", "node loads" and "internal displacements". 


\section{Structural analysis}

The structural analysis is done applying the direct stiffness method and the elastic beam deflection line equations for the internal displacements of the elements. The elements stiffness matrix, the vector of equivalent node loads and node displacements, respective to the local system are given in (1):

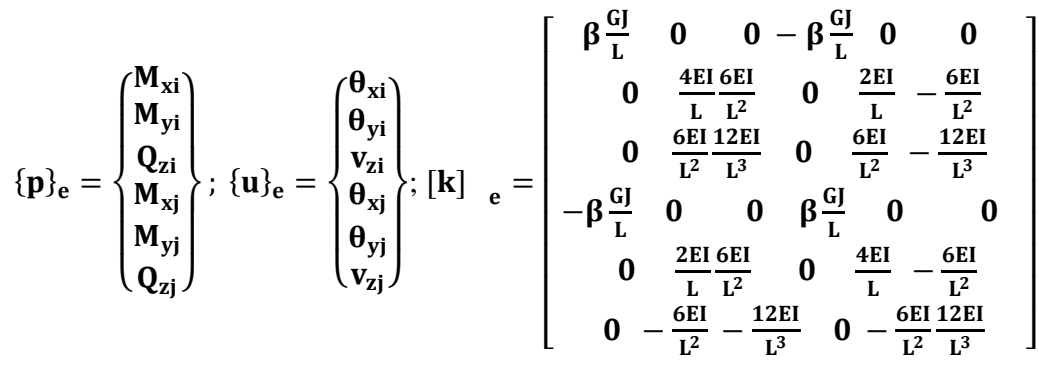

The stiffness matrix is transformed respective to the global system. Vlasov torsional stiffness effects are considered, composed of uniform and non-uniform warping stresses [2]. Due to complicated calculations and differential equation analysis, the warping effect is considered multiplying the stiffness value with a $\beta$ coefficient, evaluated from Hoogenboom [3]. The value of $\beta$ is given in (2.1),(2.2) and (2.3):

$$
\begin{gathered}
\beta=\frac{\beta_{0}}{\beta_{0}-2} ; \quad \beta>5 ; \text { when both member ends cannot warp; } \\
\beta=\frac{\beta_{0}}{\beta_{0}-1} ; \quad \beta>3 ; \text { when one member end cannot warp } \\
\beta_{0}=1 \sqrt{G I_{t} / E C_{w}}
\end{gathered}
$$

$G I_{t^{-}}$Saint Venant torsional rigidity, $E C_{w}$ - warping torsional rigidity

The total stiffness matrix of the structure is built assembling the single element stiffness matrixes respective to the global system. Applying well known stiffness matrix manipulation by Pojani [4] and Skenderi [5], free nodes displacements and internal forces of torsion, bending moment and vertical forces are evaluated for every element. Internal displacements for every beam element are evaluated too.

\section{EuroCode 3: 2005}

EuroCode resistance values represent the Constraints of the Optimal Design Problem. Ultimate limit state verification, based on EuroCode 32005 for the resistance of cross sections are done for torsion, bending and shear forces. Buckling resistance of members is evaluated for uniform members in bending and lateral torsional buckling. Service limit states are applied for the deflections of beams. Torsional resistance values for uniform and warping stresses are imposed by Trahair [6].

\section{GA algorithm}

The GA have been firstly proposed by Holland [7], in 1975. The GA algorithmic scheme, known as the Simple GA, commonly used in most applications up to now, has been further developed by Goldberg [8] in 1989. It consist in an iterative coding and decoding of the variables of the problem in a binary string of 1001010, for which is evaluated the fitness 
function of the total weight of the structure. An initial population of individuals is built. The next generations are created applying crossover and mutation operators. An Elite number defined by the designed is chosen to be part of the next generation. The algorithms stops when the convergence criteria is met:, no further improvements are achieved after a certain no. of generations.

\section{Optimal design problem variables}

Possible values of the variables are the: I-shaped standard European Commercial steel sections, from IPE 80 to IPE 600. ${ }^{1}$ All these sections are classified as Class 1.

The list of possible sections are indexed from IPE 80 to 600 with an equivalent index from 1 to 18. All the sectional properties such as height, width, cross sectional area, moment of inertia, torsional constant and others are given with their exact value.

\section{Case studies and Results}

Some case studies are analyzed with the GA algorithms. The beams are grouped in two or four variables, one or two for every elements direction. Continuous beams have the same cross sectional area. In the case of four variables, two for direction: one variable is for the $1 / 3$ of lateral beam elements, and the other for the $1 / 3$ of middle beam elements. The general scheme of the grillage structure is given in Fig. 9. The general dimensions are $\mathrm{L} \mathrm{x} \mathrm{H}$ (meters), with $r-$ 1 longitudinal beams and $n-1$ transversal ones. The beams are considered schematically with fixed ends. Detailed geometry of the grillages, and respective results are reported in Table 1. Different genetic parameters are applied in order to evaluate how the optimal weight value in a population of one generation or the best $f$, changes during the GA iterations:

'PopulationSize', 50, 'EliteCount', 20, 'MaxStallGenerations', 10-50, The 'MaxGenerations'is maintained with a value of $2 *$ no.variables. The algorithm usually ends with convergence criteria of 'MaxStallGenerations', before the 'MaxGenerations' is achieved.

\footnotetext{
${ }^{1}$ Characteristics of the cross sectional areas for these profiles can be found at www.oppo.it.
} 


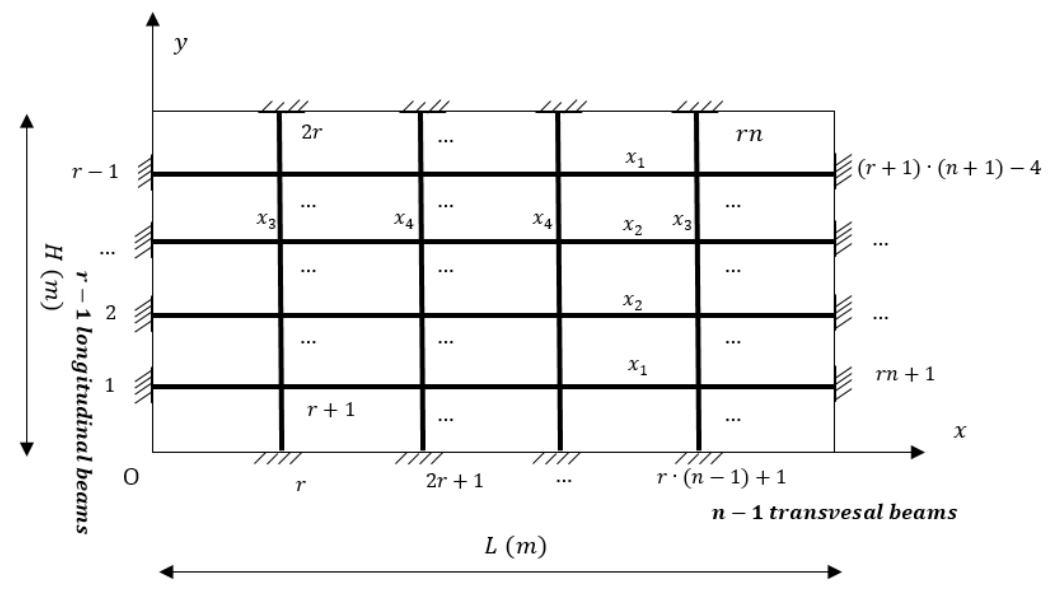

Fig. 9. General scheme of the grillage structure.

Table 1. Results of the Case studies analyzed

\begin{tabular}{|c|c|c|c|c|c|c|c|}
\hline $\begin{array}{l}\text { Grillage } \\
\text { dimension } \\
\text { L x H (m) }\end{array}$ & $\begin{array}{l}\text { No. } \\
\text { of } \\
\text { divisions } \\
n x r\end{array}$ & $\begin{array}{l}\text { Total } \\
\text { no. of } \\
\text { beams }\end{array}$ & $\begin{array}{l}\text { No. of } \\
\text { variables }\end{array}$ & $\begin{array}{l}\text { Optimal } \\
\text { variables } \\
\text { value }\end{array}$ & $\begin{array}{l}\text { Optimal } \\
\text { weight } \\
\text { value } \\
\text { bestf } \\
(\mathrm{kg})\end{array}$ & $\begin{array}{l}\text { No. of } \\
\text { generat } \\
\text { ions to } \\
\text { achieve } \\
\text { bestf }\end{array}$ & $\begin{array}{l}\text { Time } \\
\text { to } \\
\text { bestf } \\
\text { (s) }\end{array}$ \\
\hline $15 \times 10$ & $5 \times 5$ & 40 & 2 & $\begin{array}{l}I P E 120 \\
\text { IPE } 330\end{array}$ & $2588 \mathrm{~kg}$ & 5 & $5 \mathrm{~s}$ \\
\hline $30 \times 12.5$ & $10 \times 5$ & 85 & 2 & $\begin{array}{l}\text { IPE } 140 \\
\text { IPE } 400\end{array}$ & $9006 \mathrm{~kg}$ & $5-10$ & $10 \mathrm{~s}$ \\
\hline $16 \times 16$ & $10 \times 10$ & 117 & 2 & $\begin{array}{l}I P E \\
\text { IPE } 200\end{array}$ & $16286 \mathrm{~kg}$ & $5-10$ & $10 \mathrm{~s}$ \\
\hline $16 \times 16$ & $10 \times 10$ & 117 & 4 & $\begin{array}{l}\text { IPE } 80 \\
I P E 550 \\
I P E 240 \\
I P E 330\end{array}$ & $10968 \mathrm{~kg}$ & 30 & $30 \mathrm{~s}$ \\
\hline $12 \times 12$ & $10 \times 10$ & 117 & 4 & $\begin{array}{l}\text { IPE } 160 \\
\text { IPE } 550 \\
\text { IPE } 100 \\
\text { IPE } 330\end{array}$ & $7304 \mathrm{~kg}$ & 30 & $30 \mathrm{~s}$ \\
\hline
\end{tabular}

The results show that optimal values bestf are achieved after a few generations. For every generations is observed how the individuals tend to uniform respective to optimal weight values.

Higher values of 'PopulationSize'than 50, 'EliteCount' than 20, and convergence criteria 'MaxStallGenerations'than 10, does not bring further improvement of the best $f$. Results are compared with two other studies of Saka [9] and Erdal [10], for the schemes analyzed under similar conditions. 


\section{Conclusions}

Applying optimization algorithms, the engineering design process is automated with direct output result the cross sections of the beam elements. Some schemes with different dimensions have been optimally designed.

Transversal beam elements along the shorter distance are optimally sized with more rigid cross sections, compared to the longitudinal one. They behave as a unique beam with fixed ends loaded by uniform load and equivalent concentrated load transferred by the longitudinal beams. At the opposite the longitudinal beams with lower rigid sections, behave as continuous beams with internal support settlements. The results have reported best $f$ values $10 \%$ lower compared to other studies of Saka and Erdal.

Also, the analysis of the values of the best $f$ in a generation shows that the efficacy of the GA algorithm in finding the best optimal value is guaranteed. In contrast, the no. of variables and the necessary iteration time increases proportionally.

Further it was analyzed how some GA parameters influence the process. It was observed that above some values, there are no further improvements for the algorithm. The efficacy of the GA algorithm applied in the analyzed schemes resulted satisfactory, further studies are necessary on the efficiency of the algorithm.

\section{References}

1. U. Kirsch, Structural Optimization, Fundamentals and applications, Springer-Verlag, (1993).

2. V. Z. Vlasov, Thin-Walled Elastic Bars (in Russian),, Moscow: 2nd ed., Fizmatgiz, (1959).

3. P. C. J. Hoogenboom and A. Borgart, "Method for including restrained warping in traditional frame analyses," HERON, vol. 50, no. No. 1, pp. 55-68, (2005).

4. N. Pojani, N. Lako, M. Baballeku and R. Luka, Analiza matricore e strukturave, Tirana: TOENA, (2014).

5. S. Skenderi, N. Pojani, N. Lako and F. Softa, Teoria e Struktuave: Statika, Tirane: Libri Universitar, 1990.

6. N. Trahair, M. Bradford, Nethercot DA and L. Gardner, in The behaviour and design of steel structures to EC3, Oxford, Taylor \& Francis , 2007, pp. 227-290.

7. J. Holland, Adaptation in Natural and Artificial Systems, USA: MIT Press, (1975).

8. D. E. Goldberg, Genetic Algorithms in Search, Optimization \& Machine Learning, Addison Wesley, (1989).

9. M. P. Saka, A. Daloglu and F. Malhas, "Optimum spacing design of grillage systems using a genetic algorithm," Advances in Engineering Software, vol. 31, p. 863 \pm 873 , 2000.

10. F. Erdal, E. Dogan and P. M. Saka, "An improved particle swarm optimizer for steel grillage systems," Structural Engineering and Mechanics, vol. 47, pp. 513-530, 2013. 